\title{
STRUCTURAL REHABILITATION AND REAL TIME MONITORING OF THE "PONTE DELLE GRAZIE" BRIDGE IN FAENZA, ITALY
}

\author{
G. Corsi ${ }^{1}{ }^{*}$, F. Frediani ${ }^{1}$, M. La Monica ${ }^{2}$, M. Lapi ${ }^{3}$, L. Miccinesi $^{3}$, M. Micheloni $^{2}$, M. Pieraccini $^{3}$ \\ ${ }^{1}$ Move Solutions, Milan, Italy \\ ${ }^{2}$ Studio Micheloni, Florence, Italy \\ ${ }^{3}$ Università degli Studi di Firenze, Florence, Italy
}

KEY WORDS: Bridge, Structural Rehabilitation, Dynamic Tests, Monitoring

\begin{abstract}
:
The "Ponte delle Grazie" is a three spans bridge, with a total length of 72 meters, built between 1948 and 1952 in Faenza, Italy. The reinforced concrete main beams of the deck have undergone a strong deterioration over the years. In detail atmospheric agents and chemical aggressions caused a strong deterioration of the concrete, up to the point of making the structure not accessible and at risk of collapse. In fact, the five main beams were heavily damaged, as well as the concrete bearings were strongly compromised. So, an urgent intervention was necessary to save the structure of this historic bridge. A delicate restoration has allowed to remove the deteriorated concrete and to restore the resistant sections with new materials compatible with the old remaining structures. In particular, a specific rehabilitation procedure was studied using fiber-reinforced cement mortar with low elastic modulus, that is shrinkage compensated, in combination with composite materials reinforcements. Without modifying the structural behavior of the bridge, the deteriorated concrete was restored and reinforced, in a sustainable way, in order to make the structure safe and usable again. After the restoration and reinforcement the bridge capacity satisfy a reduced live load useful for urban traffic. After the restoration and reinforcement the bridge capacity satisfy a reduced live load useful for urban traffic. Even if the structure has returned to be suitable for vehicular traffic, it has been necessary to set up a real-time monitoring system, which monitors the live load and the behavior of the bridge. In detail it is used a system of geophones, that are able to detect the displacement of structures by integrating in time their response. They can provide continuous health monitoring of the bridge by transmitting the data to a remote server.
\end{abstract}

\section{HISTORY AND DESCRIPTION OF "PONTE DELLE GRAZIE”}

The "Ponte delle Grazie" is a three span bridge, with a total length of 72 meters, designed and built between 1948 and 1952 in Faenza, Italy. The bridge has a historical value linked not only to its age but also to its role as a link between the two oldest parts of the city: the historic center of Faenza and the Borgo Durbecco. In the last years a strong deterioration of concrete was find in the main beams of the lateral spans, in the Gerber half joints of the central span and in the reinforced concrete bearings on the breast walls of abutment. The deterioration of the concrete was extended up to the point of making the structure not accessible and at risk of collapse and an urgent intervention was necessary to save the structure of this historic bridge, following the procedure described in the following.

\subsection{Description of the bridge}

The bridge belongs to the category of "Gerber Bridge" (isostatic) with three spans with "internal half joints". The type in question was usually used when it was desired to have an advantageous distribution of the stresses in the structure (less positive moments in exchange for negative moments on the supports), without renouncing the advantages of the isostaticity.

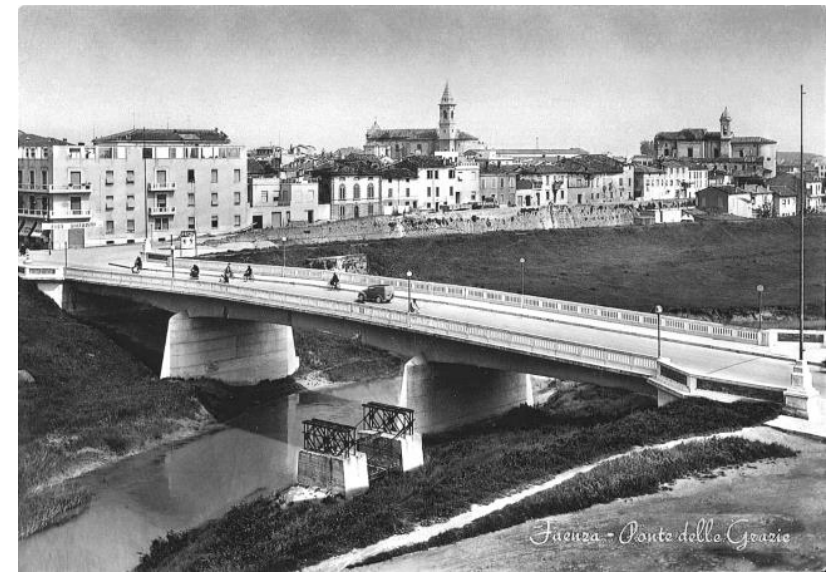

Figure 1. The "Ponte delle Grazie" bridge located on the Lamone River in an original postcard.

The disadvantage of this structural typology is that the detail in the beam seat region represents a potentially sensitive structural detail. The side spans have a length of 21 meters, while the central span has a total length of 30 meters. The part of the bridge between the two piers is made by two 6 meters cantilever spans with a suspended span of 18 meters between them. The connection between cantilever and central span is made with Gerber half joints. The total length of the bridge is 72 meters. The cross section of the deck is made of 5 beams of variable

\footnotetext{
* Corresponding author-gabriele@movesolutions.it
} 
height in reinforced concrete with $240 \mathrm{~cm}$ wheelbase. and connected with stringers. The total deck width is 13 meters.

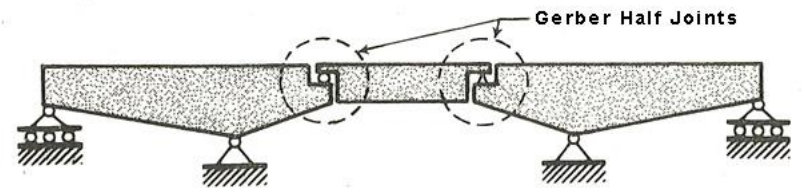

Figure 2. The structural scheme of the bridge with two Gerber half joints inside the central span.

\subsection{History of the bridge}

The bridge was designed in 1949 and built between 1950 and 1952. The original project of the bridge and many documents regarding its construction are conserved at "Archivio di Stato di Faenza", and so it was possible to analyze and study these documents to increase the knowledge of the bridge.

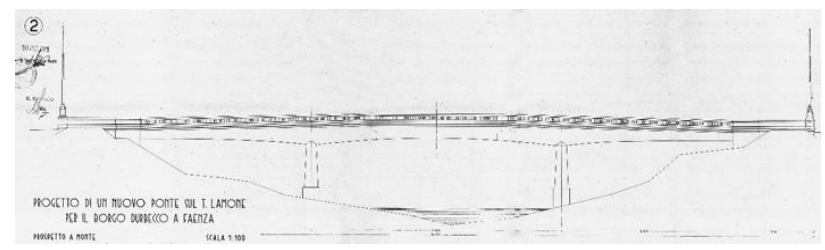

Figure 3. The elevation of "Ponte delle Grazie" in the original drawings from "Archivio di Stato di Faenza".

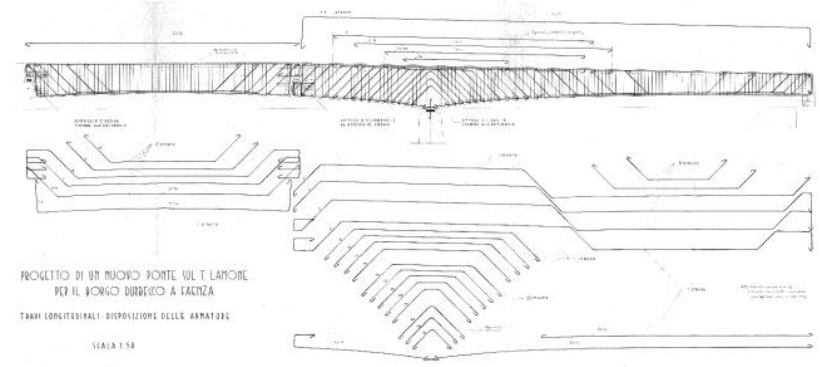

Figure 4. Main beams rebars design in the original drawing from "Archivio di Stato di Faenza".

\section{THE KNOWLEDGE PROCESS}

The knowledge of the structure and its state of conservation goes through the analysis of the following steps:

- Analysis of the deterioration of the concrete and reinforcement steel

- Analysis of materials

- Analysis of the structure and its service level.

\section{THE DETERIORATION OF THE CONCRETE AND REINFORCEMENT STEEL}

The first task to be carried out was the identification of the critical aspects of the structure and its deterioration.

The most critical deterioration was found in the following parts:

- Main beams of the side spans

- Gerber half joints of the central span

- Reinforced concrete bearings on the breast walls of abutment.
The main beams of the side spans presented a strong deterioration, especially near the abutment, as demonstrate by visual inspections and laboratory tests on materials.

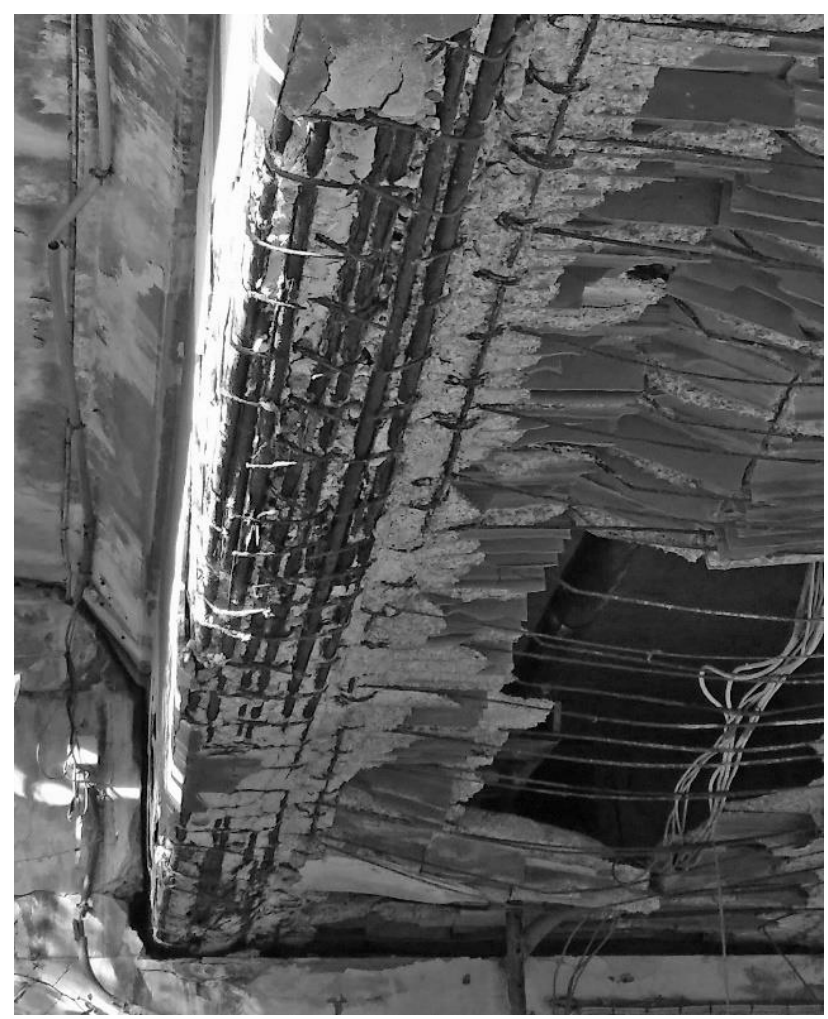

Figure 5. Beams deterioration on the side span.

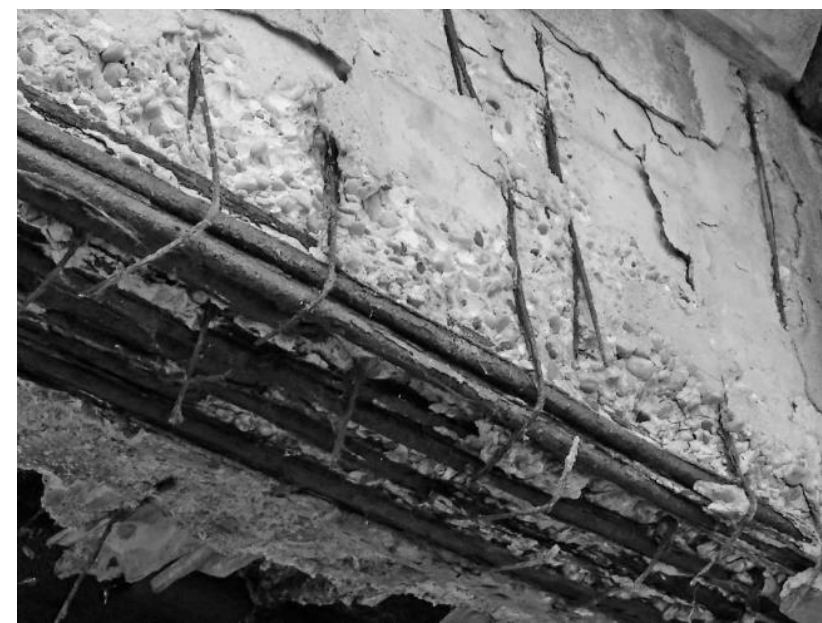

Figure 6. Beams deterioration on the side span.

The dangerous state of the main beams in the area near to the abutments was evident. In fact not only the concrete is strongly damaged, but also the steel bars are deeply corroded and the stirrups are exploded.

The main beams of the side spans rest on the breast walls with reinforced concrete bearings. This kind of "pendulum bearing" is made with reinforced concrete and they represent a very sensitive detail.

In detail this concrete bearings exhibit a strong degradation phenomena, with evident breaking lesions in place, as evidenced by the following images. 
The dangerous state of the supports is evident and it has become necessary to take urgent action.

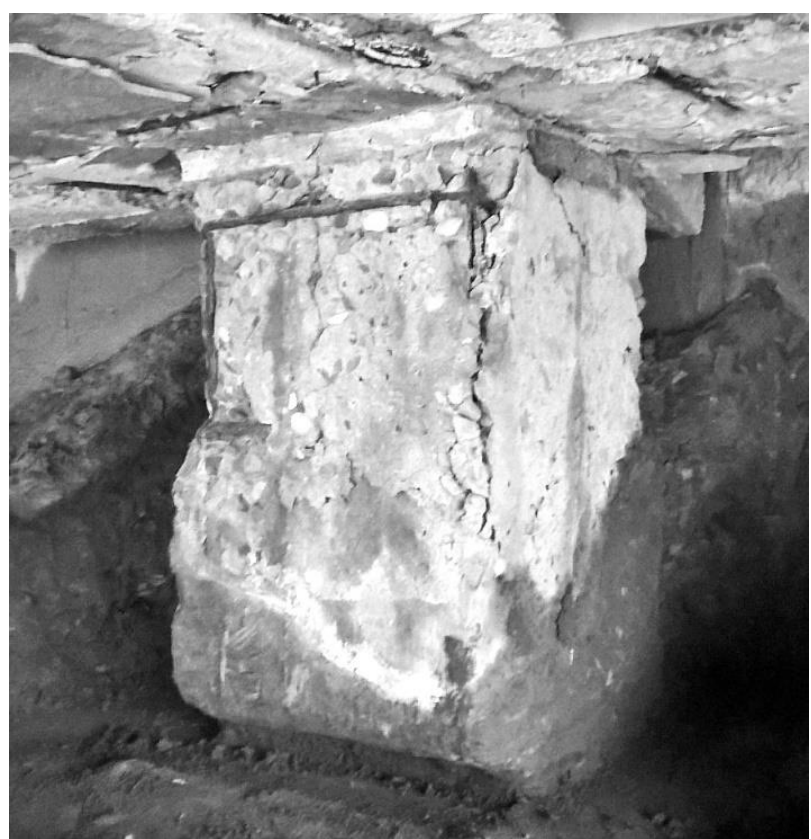

Figure 7. Deterioration and cracks on the concrete pendulum bearing.

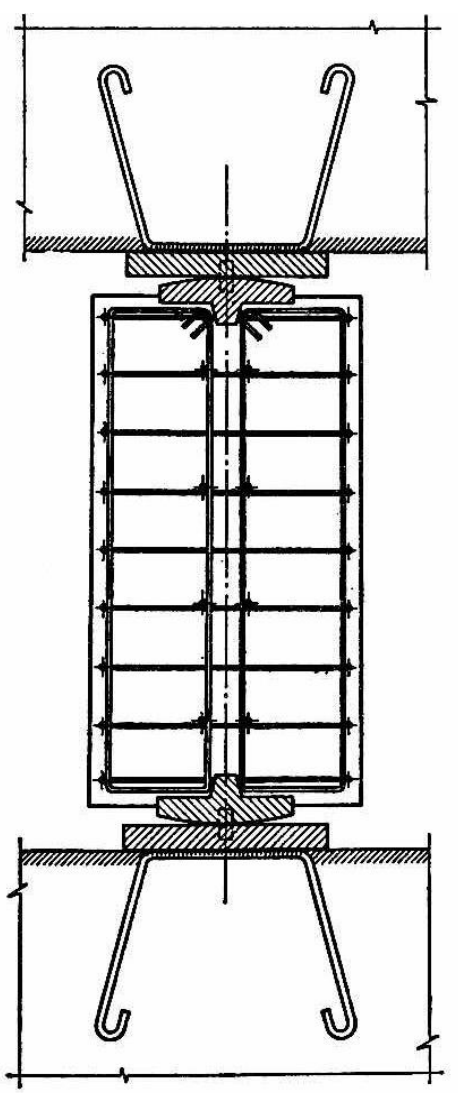

Figure 8. Concrete pendulum bearing typical scheme (Pozzati and Ceccoli, 1977, fig. 3.38, p. 223).

\section{THE STRUCTURAL REHABILITATION AND REINFORCEMENT PROCESS}

The structural rehabilitation and reinforcement (Micheloni et al., 2018) follow two approaches:

- Repair of concrete and reinforcement of the bearings on the abutment and of the side span of the main beams

- Install of new steel structures to protect the bearings on the abutment and the Gerber half joints.

In fact, the desire to maintain the original scheme of the bridge, in a sustainable way, requires not only to repair and reinforce the concrete, but also to insert new structures to protect the most delicate parts. The main beams of side spans and the concrete pendulum bearing were repaired and reinforced to comply with the requirements of the loading scheme.5. Moreover the Gerber half joint and the concrete pendulum bearing are very critical structural details, so, even if the structural check is satisfied, a new "protection" structures are placed on these parts.

\subsection{Main beams rehabilitation and reinforcement}

The main beams of the side spans are repaired with a deep cleaning and restoration of concrete and reinforced with a wrapping of carbon fiber textiles.

The phases of these works are the following:

- Deep cleaning of concrete surfaces with high pressure hydro-scarification (2000 bar)

- Reconstruction of the concrete section with a twocomponent thixotropic, fiber-reinforced cement mortar with low elastic modulus that is shrinkage compensated.

- Wrapping with carbon fiber textiles.

In the areas where the cognitive tests on the concrete had given the lowest results, a large quantity of deteriorated concrete was removed. In these points the $40 \mathrm{~cm}$ wide beam has been reduced to only $18 \mathrm{~cm}$.

The reconstruction phase was very critical, because it was very important to guarantee the perfect adhesion of the new cement mortar to the existing concrete. In the mean time the new material must have the same low elastic modulus of existing concrete. To comply with these requirements a specific twocomponent thixotropic, fiber-reinforced cement mortar was selected. Some pull-off tests are performed to check the adhesion between the new and old concrete.

Inside the new part of concrete reconstruction, a steel net and some steel bars are placed to increase the reinforcement bar cross-section, that was lost due to corrosion.

After the reconstruction of the beam section a wrapping with carbon fiber textiles of $1000 \mathrm{gr} / \mathrm{sqm}$ was necessary to satisfy the verification for the shear loads, in accordance with the CNR-DT code (CNR-DT 200R1/2013).

A specific detail is designed to wrap the FRP textiles around the beam cross-section. In the lower part of the beam the FRP textile can be laid on the beam surface, but to pass true the deck slab, it is necessary to place the FRP textile true holes with $30 \mathrm{~mm}$ diameter.

\subsection{Reinforced concrete bearings rehabilitation and reinforcement}

The reinforced concrete pendulum bearings are repaired with a soft cleaning and restoration of concrete and reinforced with a wrapping of carbon fiber textiles. In this way the bearing strengthening is verified considering a reduced loading scheme. 
However, it is important to consider the particularity and delicacy of this kind of bearing. So there is no guarantee that the actual situation can get worse without the possibility of intervention.

For these reasons some steel columns are put in place as a structure of defense, that comes into operation only in case of collapse of the concrete bearings.

\section{DYNAMIC TESTS AND MONITORING SYSTEM}

The quality of the work was confirmed by a complete series of final test on the materials and on the structure. In particular a specific set of static and dynamic test with vehicle loads were performed on the entire bridge structure.

In detail the static tests demonstrate the safety of the structure and the correct execution of the works, but it is very interesting to underline the results of dynamic testing through microwave interferometry (Pieraccini et al., 2007).

In fact, as a result of the reinforcement works, there was an increasing of the natural frequency of the structure of about $0,15 \mathrm{~Hz}$. This value is synonymous with a substantial increase in bridge deck stiffness.

Even if the structure has returned to be suitable for vehicular traffic, it has been necessary to set up a real-time monitoring system, which monitors the live load and the behavior of the bridge. In detail it is used a system of geophones, that are able to detect the displacement of structures by integrating in time their response.

They can provide continuous health monitoring of the bridge by transmitting the data to a remote server.

In detail a a particular device made with an analog compensated geophone has been created by the joint venture between Move Srl and Studio Micheloni Srl.

The performance of the geophone sensor has been experimentally compared with an interferometric radar in a controlled environment and during some site tests.

A network of six geophones, operating in threshold-mode, was installed under the spans of the bridge in order to provide continuous monitoring under the road live load.

\section{THE GEOPHONE SENSOR FOR THE MONITORING SYSTEM}

The monitoring of the bridge is performed with a system of compensated geophone sensors.

A block scheme of the geophone sensor is shown in figure 9 . The geophone is able to measure the speed-changing of a structure in the gravity direction. Its response is integrated to obtain the displacement using an analog integrator.

The displacement is digitized by a 10 bit $\mathrm{A} / \mathrm{D}$ converter. The control unit provides a $100 \mathrm{~Hz}$ clock to A/D converter and it manages the buffer and the communication with the server. The device is able to send data to a remote server via LoRaWAN network or via USB cable. A battery unit provides the power supply for each device and it ensures an operating time of one/two weeks.

The battery unit can be recharged by a solar panel for operating indefinitely.

The geophone sensor is able to detect displacement in the band $1 \mathrm{~Hz}-20 \mathrm{~Hz}$. The device can work in debug-mode or threshold-mode. In the debug-mode, the device is able to provide a continuous measurement and it sends all recorded data via USB.

The debug-mode can be used for laboratory test or in a controlled environment.
The threshold-mode is used for infield operations. In this case the control unit checks the last value of the measurement and if it is larger than a fixed threshold, it sends a packet with $40 \mathrm{~s}$ data (20s before and $20 s$ after threshold) to a remote server. The threshold can be adjusted for different applications.

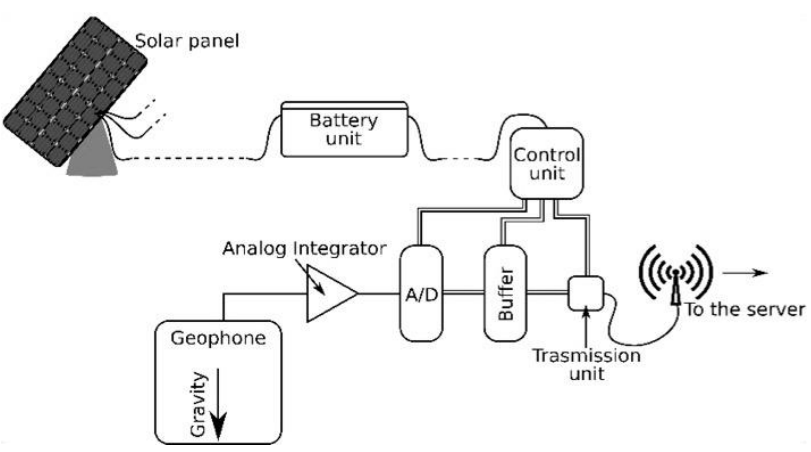

Figure 9. Block scheme of geophone sensor.

\section{DATA ANALYSIS AND DATA VISUALIZATION}

The server is able to manage the devices installed on the bridge and the final user can access to the main data of the structure. It is possible to analyse the collected data on the server. The data are stored in an online database and an application server is used to elaborate and verify the collected data. A simple user interface let the user pick the device that want to analyse, as shown in figure 10 .

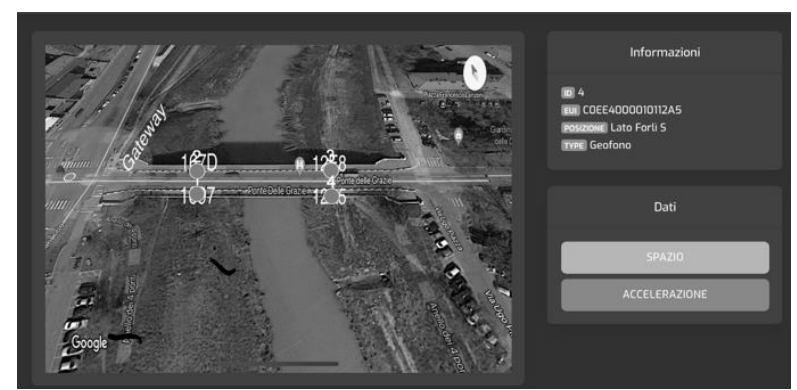

Figure 10. user interface to handle geophone sensors.

The application server shows in graphs the data collected plotting amplitude and the Fast Fourier transform for each sampled event as shown in figure 11 and 12 .

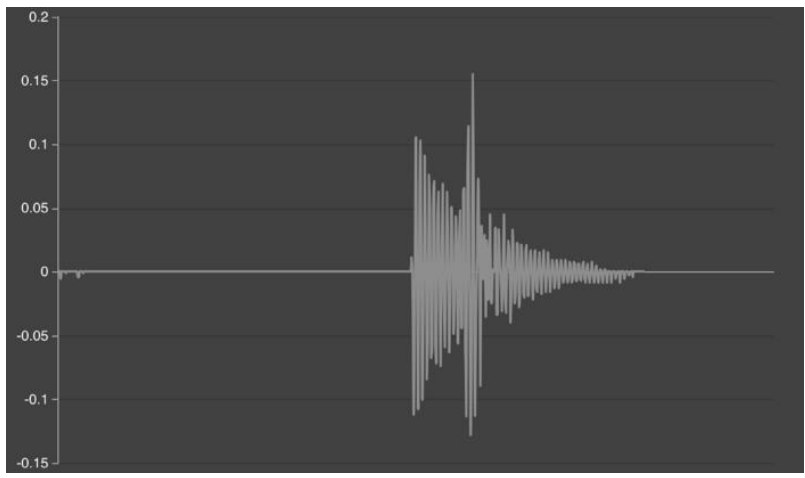

Figure 11. Amplitude over time plot. 


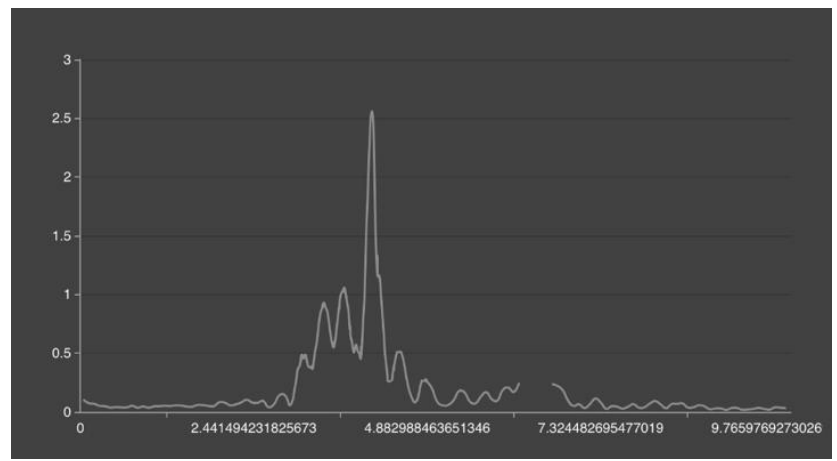

Figure 12. FFT plot.

\section{CONCLUSION}

At the end it is possible to conclude that the delicate restoration work with specific materials and procedures, has allowed to reinforce the bridge, in a sustainable way, in order to make the structure safe and usable again. A specific monitoring system with innovative geophones will be used to correctly capture the dynamic behaviour of the bridge under road live loads.

\section{REFERENCES}

“Archivio di Stato di Faenza”, fondo b.51/1952.

CNR-DT 200R1/2013. "Istruzioni per la Progettazione, l'Esecuzione ed il Collaudo di Interventi di Consolidamento Statico mediante l'utilizzo di Compositi Fibrorinforzati", Consiglio Nazionale delle Ricerche Italiano, 10 ottobre 2013, 2014/05/15 version.

Micheloni, M., La Monica, M., Parmeggiani, D., Barchi, P., 2018. Sustainable structural rehabilitation and strengthening of the "Ponte delle Grazie" bridge in Faenza, Italy - Fib Conference. IOP Conf. Ser.: Mater. Sci. Eng., 442, 1-11.

Pieraccini, M., Parrini, F., Fratini, M., Atzeni, C., Spinelli, P., Micheloni, M., 2007. Static and dynamic testing of bridges through microwave interferometry. NDT\&E International, 40, 208-214.

Pozzati, P., Ceccoli, C., 1977. Teoria e tecnica delle strutture. vol 2, tomo 2, Turin, Utet. 